\title{
Non-Invasive Brain Stimulation and its Supposed Site of Action in the Rehabilitation of Parkinson's Disease and Stroke Judit Mally*
}

Head of the Institute of Neurorehabilitation, Sopron, Hungary

Two non-invasive brain stimulations have spread all over the world: repetitive trasncranial magnetic stimulation (rTMS) and transcranial direct current stimulation (tDCS). TMS is based on the current induction with a changing electromagnetic field in the nervous system [1] while tDCS changes the polarity of cell membranes [2].

\section{General Aspects of TMS and tDCS}

TMS is widely used in research and daily medical practice. It was introduced as a diagnostic tool about thirty years ago to test functioning of motor pathways [3]. The motor evoked potential (MEP) and the measurement of the central motor conduction time (CMCT) has entered into daily practice. The other parameters of the electrophysiological examination assessed by TMS are mainly used in scientific work [4]. TMS aids the diagnosis of multiple sclerosis, furthermore the prognosis of stroke can be indicated by TMS [5] Different paired pulse stimulations with TMS give a new insight into the function of the brain. In recent years, sophisticated brain plasticity can be detected by the measurement of intracortical excitability [6,7]. We learnt from these studies how different conditions can modify brain plasticity. It can be changed by different diseases, altered by drugs [8] and strongly influenced by non-invasive stimulations [2,9]. The single TMS and one session of repetitive stimulation have a short after-effect. However the effect of repeated stimulation for days exceeds the stimulation period and many times it lasts for months. This effect of rTMS has made it useful for therapy for the last 20 years. The low and high frequency stimulation, continuous theta burst stimulation (cTBS), intermittent theta burst stimulation (iTBS), anodal or cathodal stimulation are used for therapy. The intensity of rTMS was around the motor threshold and the duration of stimulation was 7-10 days. This paper reviews the most frequently studied symptoms of Parkinson's diseases and stroke although rTMS has been tried to treat all disorders of the central nervous system (CNS).

\section{Parkinson's Disease (PD)}

The first protocol was low frequency, low intensity monophasic stimulation for 7 days which improved the Parkinsonian symptoms and its results were maintained for several months after the stimulation $[10,11]$. The authors performed a "dose (intensity) response" curve with $1 \mathrm{~Hz}$ stimulation and they indicated that there is an optimal intensity using $1 \mathrm{~Hz}$ [12]. We learned from these studies that the therapeutic effect of rTMS develops after a delay in time of a few weeks. The improvement can be maintained for several months. The later studies confirmed these observations not only in PD but other diseases. Although, the high frequency stimulations over the primary motor cortex $[13,14]$ had the same effect on the Parkinsonian scores but the after-effect lasted for a shorter time. iTBS over the dorsolateral prefrontal area improved the depression without effecting on bradykinesia [15]. The studies concentrated on varying the frequency which was applied but they did not try to find the optimal intensity for high frequency stimulation. Using the optimal intensity will produce longer lasting therapeutic effects. The cure of levodopa induced dyskinesia is far more can not be solved. Although, the dyskinesia induced by levodopa can be decreased by low frequency rTMS over the primary motor cortex or cTBS over the cerebellum [16,17]. rTMS over the motor cortex induced dopamine release in ipsilateral putamen assessed by [11C] raclopide
PET study, which also contribute to the effect of rTMS in PD [18]. The regularly repeated rTMS periods may decrease the development of PD [19]. This observation needs further confirmation. The motor deficit of Parkinson's disease can be influenced by tDCS applied parallel over the motor and prefrontal area [20]. Similarly to the rTMS, one of the supposed sites of action of tDCS - according to animal studies - is the dopamine release in the striatum [21]. These promising results urge the involvement of non-invasive brain stimulation in the treatment of Parkinson's disease because the respond for dopaminergic therapy is less effective over years.

\section{Influence on Different Symptoms of Stroke with Non- Invasive Brain Stimulation}

The most frequently observed stroke happens in the area of the artery of the cerebral media. It may cause different symptoms such as paresis, spasticity, aphasia, neglect dysphagia and cognitive decline.

There is a mutual inhibition between the two hemispheres which is destroyed by a lesion caused by stroke. The goal of the treatment with non-invasive brain stimulations is to restore the decreased excitability of the lesioned hemisphere and decrease the over activity of the nonlesioned hemisphere [22]. Low frequency stimulation and cTBS stimulation are applied over the non-lesioned hemisphere to decrease the excitability, while the high frequency and iTBS stimulation enhances the excitability and they are used over the lesioned hemisphere. Both treatments led to a faster movement in the paretic hand, and decreased the reaction time in slight cases of stroke [23-26]. The $3 \mathrm{~Hz}$ stimulation showed a more pronounced effect than $10 \mathrm{~Hz}$ stimulation assessed by NIHSS after one year [27]. The best results were achieved after $1 \mathrm{~Hz}$ stimulation [28] which induced new movement in the paretic hand years after the onset of stroke [29]. A meta-analysis confirmed that 1 $\mathrm{Hz}$ rTMS over the unaffected hemisphere may be more beneficial for the motor outcome than the high frequency rTMS over the affected hemisphere [30]. The motor deficit of stroke can also be treated by tDCS.

The same positive results with tDCS as rTMS confirmed the effectiveness of anodal and cathodal stimulations for 6 days. Both stimulations were superior to sham stimulation over the primary motor cortex in a three month follow up study [31]. The usefulness of tDCS in chronic stroke was summarized by Stagg [32]. There are controversy results in the long term usefulness of speech therapy in fluent aphasia, but the non-invasive stimulation over the language area can improve

*Corresponding author: Judit Mally, Head of the Institute of Neurorehabilitation, Sopron, Hungary, Tel: 20-392-0031; Email: mally.judit@t-online.hu

Received January 28, 2014; Accepted February 15, 2014; Published February 25,2014

Citation: Mally J (2014) Non-Invasive Brain Stimulation and its Supposed Site of Action in the Rehabilitation of Parkinson's Disease and Stroke. Int J Neurorehabilitation 1: e103. doi:10.4172/2376-0281.1000e103

Copyright: (c) 2014 Mally J. This is an open-access article distributed under the terms of the Creative Commons Attribution License, which permits unrestricted use, distribution, and reproduction in any medium, provided the original author and source are credited. 
the object naming, although, several weeks after the stimulation. It was demonstrated by rTMS [33-36] and tDCS [37,38]. There is a reversion of the imbalance of interhemispheric inhibition, speech induced activity shifts to the left side instead of both sides or right side and formation of a new language network which may responsible for the better outcome of aphasia several weeks after stimulation.

In addition, both neglect and dysphagia can be improved by noninvasion brain stimulation. Neglect makes the improvement of paretic extremities more difficult. It can be ameliorated by one $\mathrm{Hz}$ stimulation over the right parietal cortex [39]. Dysphagia is a life threatening symptom of a brain injury. It is caused by pseudobulbar paralysis or a lesion in the brain stem which was improved after rTMS [40,41]. In addition to the wide therapeutic application of rTMS the spasticity can also be decreased by rTMS with low and high frequency stimulation $[25,42]$.

Cognitive impairment appears not only in Alzheimer's disease, but it accompanies many diseases. The most prominent examples are brain injuries, stroke and different neurodegenerative diseases. The working memory and executive function can be improved by low and high frequency stimulation over the dorsolateral prefrontal cortex but not over the primary motor cortex in patients with stroke [43]. The working memory and visuo-motor learning were facilitated by tDCS $[44,45]$. The effect of non-invasive stimulations depends on the tasks performed in the study which may contribute to the great variability of the results. It was summarized by Miniussi [46].

Depression is an independent entity but many times accompanies other chronic diseases. No unified protocol for the treatment of depression has been settled. The FDA accepted treatment with high frequency stimulation of drug resistant cases. Similarly to the previous symptoms, depression can be improved by low and high frequency stimulation of rTMS $[47,48]$. The right dorsolateral prefrontal cortex (DLPFC) was stimulated by low frequency while the left DLPFC was treated with high frequency stimulation. Both were equally effective according a meta-analysis [49]. The previous symptoms can be influenced at the same time by non-invasive stimulations. This possibility is the great advantage to these therapies.

\section{Proposed Site of Action of Non-Invasive Brain Stimulation}

The question is whether the change in intracortical excitability is responsible for the therapeutic effect of the brain stimulation. At the beginning, the therapeutic use was based on influencing brain plasticity but there is a time delay in the two effects of rTMS. The effect on brain plasticity develops immediately and ceases at the end of the stimulation but the therapeutic effect develops over a period of weeks or months. This discrepancy in time led to the conclusion that TMS and tDCS influence both of them but the two effects are partly independent from one another [50].

In animal studies, the production of stem cells under the subventicular zone and their migration to the lesioned area was increased after rTMS [51,52]. If this is true in humans as well, rTMS will not only be a symptomatic treatment but it could be used to influence the etiology of the disease. BDNF is the regenerating hormone for the nervous system and rTMS and tDCS increases its production [53-56].

The effects of rTMS and tDCS are not localized but the activity of the central nervous system is increased or decreased far from the place that was stimulated. We cannot exclude the possibility that non-synpatic transmission contributes to the effect of non-invasive stimulations because the non-stimulated parts of the brain are also activated by non-invasive stimulations [57]. GABA is increased in the cortex after low frequency stimulation [58,59]. After high frequency stimulation, the glutamate is increased [60]. There is a new balance between the inhibitory and excitatory neurotransmitter system which is achieved by the rTMS and tDCS [61].

Therefore the mode of action of rTMS and tDCS may be similar in restoring impaired neuronal activity which prepares the intact part of the brain for better functional activity.

\section{Difficulties in Therapy with Non-Invasive Brain Stimulation}

The results of different publications are hardly comparable because of the great variations of protocols. Two modes of TMS stimulation are applied, monophasic and biphasic, which basically differ from each other. Consequently the same intensity and frequency do not mean the same electric current induced by the stimulation. Furthermore intracortical excitability can be facilitated by high frequency stimulation and inhibited by low frequency stimulation but the individual values present a great variability which may lead to different therapeutic effects. The variability depends on which interneuron network is affected by TMS in the subject [62]. The heterogeneity of a group of patients may lead to divergent results.

\section{Conclusions}

Both non-invasive brain stimulations improve different symptoms of central nervous diseases. The effect develops slowly and can be maintained for months after the stimulation. It seems that both the low and high frequency stimulations effective but the intensity and duration of stimulation must be adjusted to each other. They influence both neuroplasticity and symptoms of the disease but their effect may partly independent from each other. The therapeutic effect may be attributed to the elevated brain stem production, increased levels of BDNF, a new balance in the inhibitory and excitatory neurotransmitter and in addition the non-synaptic transmission may play a role in the healing effect of non-invasive stimulation.

While the stimulation of motor pathways quickly spread all over the world, therapeutic use of repetitive stimulation remained restricted to electro physiologists and has hardly touched the daily practice of neurology and rehabilitation. During the last twenty years nearly one thousand patients with different diseases were involved in the studies where results showed a significant improvement in most cases. These are safe methods (guidelines exist) and we have to use them to benefit our patients.

\section{References}

1. Di Lazzaro V, Restuccia D, Oliviero A, Profice P, Ferrara L, et al. (1998) Effects of voluntary contraction on descending volleys evoked by transcranial stimulation in conscious humans. J Physiol 508: 625-633.

2. Nitsche MA, Paulus W (2000) Excitability changes induced in the human motor cortex by weak transcranial direct current stimulation. J Physiol 3: 633-639.

3. Barker AT, Jalinous R, Freeston IL (1986) Non-invasive magnetic stimulation of human motor cortex. Lancet 1: 1106-1107.

4. Chen R, Cros D, Curra A, Di Lazzaro V, Lefaucheur JP, et al. (2008) The clinical diagnostic utility of transcranial magnetic stimulation: report of an IFCN committee. Clin Neurophysiol 119: 504-532.

5. D'Olhaberriague L, Espadaler Gamissans JM, Marrugat J, Valls A, Oliveras Ley $C$, et al. (1997) Transcranial magnetic stimulation as a prognostic tool in stroke. J Neurol Sci 147: 73-80. 
6. Kujirai T, Caramia MD, Rothwell JC, Day BL, Thompson PD, et al. (1993) Corticocortical inhibition in human motor cortex. J Physiol 471: 501-519.

7. Ridding MC, Taylor JL (2001) Mechanisms of motor-evoked potential facilitation following prolonged dual peripheral and central stimulation in humans. J Physiol 537: 623-631.

8. Ziemann U, Lönnecker S, Steinhoff BJ, Paulus W (1996) Effects of antiepileptic drugs on motor cortex excitability in humans: a transcranial magnetic stimulation study. Ann Neurol 40: 367-378.

9. Pascual-Leone A, Valls-Solé J, Wassermann EM, Hallett M (1994) Responses to rapid-rate transcranial magnetic stimulation of the human motor cortex. Brain 117: 847-858.

10. Mally J, Stone TW (1998) Lasting improvement in parkinsonian symptoms after repetitive transcranial magnetic stimulation. Med Sci Res 26: 521-523.

11. Mally J, Stone TW (1999) Improvement in Parkinsonian symptoms after repetitive transcranial magnetic stimulation. J Neurol Sci 162: 179-184.

12. Mally J, Stone TW (1999) Therapeutic and "dose-dependent" effect of repetitive microelectroshock induced by transcranial magnetic stimulation in Parkinson's disease. J Neurosci Res 57: 935-940.

13. Khedr EM, Rothwell JC, Shawky OA, Ahmed MA, Hamdy A (2006) Effect of daily repetitive trasncranial magnetic stimulation on motor performance in Parkinson's disease. Mov Disord 21: 1311-1316.

14. Khedr EM, Farweez HM, Islam H (2003) Therapeutic effect of repetitive transcranial magnetic stimulation on motor function in Parkinson's disease patients. Eur J Neurol 10: 567-572.

15. Benninger DH, Berman BD, Houdayer E, Pal N, Luckenbaugh DA, et al. (2011) Intermittent theta-burst transcranial magnetic stimulation for treatment of Parkinson disease. Neurology 76: 601-609.

16. Koch G, Brusa L, Carrillo F, Lo Gerfo E, Torriero S, et al. (2009) Cerebellar magnetic stimulation decreases levodopa-induced dyskinesias in Parkinson disease. Neurology 73: 113-119.

17. Koch G (2010) rTMS effects on levodopa induced dyskinesias in Parkinson's disease patients: searching for effective cortical targets. Restor Neurol Neurosci 28: 561-568.

18. Strafella AP, Ko JH, Grant J, Fraraccio M, Monchi O (2005) Corticostriatal functional interactions in Parkinson's disease: a rTMS/[11C]raclopride PET study. Eur J Neurosci 22: 2946-2952.

19. Málly J, Farkas R, Tóthfalusi L, Stone TW (2004) Long-term follow-up study with repetitive transcranial magnetic stimulation (rTMS) in Parkinson's disease. Brain Res Bull 64: 259-263.

20. Benninger DH, Lomarev M, Lopez G, Wassermann EM, Li X, et al. (2010) Transcranial direct current stimulation for the treatment of Parkinson's disease. J Neurol Neurosurg Psychiatry 81: 1105-1111.

21. Tanaka T, Takano Y, Tanaka S, Hironaka N, Kobayashi K, et al. (2013) Transcranial direct-current stimulation increases extracellular dopamine levels in the rat striatum. Front Syst Neurosci 7: 6 .

22. Murase N, Duque J, Mazzocchio R, Cohen LG (2004) Influence of interhemispheric interactions on motor function in chronic stroke. Ann Neurol 55: $400-409$

23. Talelli P, Greenwood RJ, Rothwell JC (2007) Exploring Theta Burst Stimulation as an intervention to improve motor recovery in chronic stroke. Clin Neurophysio 118: 333-342.

24. Fregni F, Boggio PS, Valle AC, Rocha RR, Duarte J, et al. (2006). A shamcontrolled trial of a 5-day course of repetitive transcranial magnetic stimulation of the unaffected hemisphere in stroke patients. Stroke 37: 2115-2122.

25. Kakuda W, Abo M, Kobayashi K, Momosaki R, Yokoi A, et al. (2011) Antispastic effect of low-frequency rTMS applied with occupational therapy in poststroke patients with upper limb hemiparesis. Brain Inj 25: 496-502.

26. Chang WH, Kim YH, Bang OY, Kim ST, Park YH, et al. (2010) Long-term effects of rTMS on motor recovery in patients after subacute stroke. J Rehabil Med 42: 758-764.

27. Khedr EM, Etraby AE, Hemeda M, Nasef AM, Razek AA (2010) Long-term effect of repetitive transcranial magnetic stimulation on motor function recovery after acute ischemic stroke. Acta Neurol Scand 121: 30-37.
28. Khedr EM, Abdel-Fadeil MR, Farghali A, Qaid M (2009) Role of 1 and $3 \mathrm{~Hz}$ repetitive transcranial magnetic stimulation on motor function recovery afte acute ischaemic stroke. Eur J Neurol 16: 1323-1330.

29. Málly J, Dinya E (2008) Recovery of motor disability and spasticity in poststroke after repetitive transcranial magnetic stimulation (rTMS). Brain Res Bull 76: 388-395.

30. Hsu WY, Cheng CH, Liao KK, Lee IH, Lin YY (2012) Effects of repetitive transcranial magnetic stimulation on motor functions in patients with stroke: a meta-analysis. Stroke 43: 1849-1857.

31. Khedr EM, Shawky OA, El-Hammady DH, Rothwell JC, Darwish ES, et al. (2013) Effect of anodal versus cathodal transcranial direct current stimulation on stroke rehabilitation: a pilot randomized controlled trial. Neurorehabil Neural Repair 27: 592-530.

32. Stagg CJ, Johansen-Berg H (2013) Studying the Effects of Transcranial DirectCurrent Stimulation in Stroke Recovery Using Magnetic Resonance Imaging Front Hum Neurosci 7: 857

33. Naeser MA, Martin PI, Nicholas M, Baker EH, Seekins H, et al. (2005) Improved picture naming in chronic aphasia after TMS to part of right Broca's area: an open-protocol study. Brain Lang 93: 95-105.

34. Barwood CH, Murdoch BE, Whelan BM, Lloyd D, Riek S, et al. (2011) Improved language performance subsequent to low-frequency rTMS in patients with chronic non-fluent aphasia post-stroke. Eur J Neurol 18: 935-943.

35. Szaflarski JP, Vannest J, Wu SW, DiFrancesco MW, Banks C, et al. (2011) Excitatory repetitive transcranial magnetic stimulation induces improvements in chronic post-stroke aphasia. Med Sci Monit 17: CR132-139.

36. Weiduschat N, Thiel A, Rubi-Fessen I, Hartmann A, Kessler J, et al. (2011) Effects of repetitive transcranial magnetic stimulation in aphasic stroke: a randomized controlled pilot study. Stroke 42: 409-415.

37. Baker JM, Rorden C, Fridriksson J (2010) Using transcranial direct-current stimulation to treat stroke patients with aphasia. Stroke 41: 1229-1236.

38. Marangolo P, Marinelli CV, Bonifazi S, Fiori V, Ceravolo MG, et al. (2011) Electrical stimulation over the left inferior frontal gyrus (IFG) determines longterm effects in the recovery of speech apraxia in three chronic aphasics. Behav Brain Res 225: 498-504.

39. Brighina F, Bisiach E, Oliveri M, Piazza A, La Bua V, et al. (2003) $1 \mathrm{~Hz}$ repetitive transcranial magnetic stimulation of the unaffected hemisphere ameliorates contralesional visuospatial neglect in humans. Neurosci Lett 336: 131-133.

40. Khedr EM, Abo-Elfetoh N, Rothwell JC (2009) Treatment of post-stroke dysphagia with repetitive transcranial magnetic stimulation. Acta Neurol Scand 119: 155-161.

41. Khedr EM, Abo-Elfetoh N (2010) Therapeutic role of rTMS on recovery of dysphagia in patients with lateral medullary syndrome and brainstem infarction. J Neurol Neurosurg Psychiatry 81: 495-499.

42. Kumru H, Murillo N, Samso JV, Valls-Sole J, Edwards D, et al. (2010) Reduction of spasticity with repetitive transcranial magnetic stimulation in Patients with spinal cord injury. Neurorehabil Neural Repair 24: 435-441.

43. Rektorova I, Megova S, Bares M, Rektor I (2005) Cognitive functioning after repetitive transcranial magnetic stimulation in patients with cerebrovascula disease without dementia: a pilot study of seven patients. J Neurol Sci 15 229-230.

44. Fregni F, Boggio PS, Nitsche M, Bermpohl F, Antal A, et al. (2005) Anodal transcranial direct current stimulation of prefrontal cortex enhances working memory. Exp Brain Res 166: 23-30.

45. Antal A, Nitsche MA, Kincses TZ, Kruse W, Hoffmann KP, et al. (2004) Facilitation of visuo-motor learning by transcranial direct current stimulation of the motor and extrastriate visual areas in humans. Eur J Neurosci 19: 2888 2892

46. Miniussi C, Cappa SF, Cohen LG, Floel A, Fregni F, et al. (2008) Efficacy of repetitive transcranial magnetic stimulation/transcranial direct current stimulation in cognitive neurorehabilitation. Brain Stimul 1: 326-336.

47. Stern WM, Tormos JM, Press DZ, Pearlman C, Pascual-Leone A (2007) Antidepressant effects of high and low frequency repetitive transcranial magnetic stimulation to the dorsolateral prefrontal cortex: a double-blind randomized, placebo-controlled trial. J Neuropsychiatry Clin Neurosci 19: 179 186. 
Citation: Mally J (2014) Non-Invasive Brain Stimulation and its Supposed Site of Action in the Rehabilitation of Parkinson's Disease and Stroke. Int J Neurorehabilitation 1: e103. doi:10.4172/2376-0281.1000e103

48. Eranti S, Mogg A, Pluck G, Landau S, Purvis R, et al. (2007) A randomized, controlled trial with 6-month follow-up if repetitive transcranial magnetic stimulation and electroconvulsive therapy for severe depression. Am J Psychiatry 164: 73-81.

49. Chen J, Zhou C, Wu B, Wang Y, Li Q, et al. (2013) Left versus right repetitive transcranial magnetic stimulation in treating major depression: a meta-analysis of randomised controlled trials. Psychiatry Res 210: 1260-1264.

50. Hoogendam JM, Ramakers GM, Di Lazzaro V (2010) Physiology of repetitive transcranial magnetic stimulation of the human brain. Brain Stimul 3: 95-118.

51. Arias-Carrión O (2008) Basic mechanisms of rTMS: Implications in Parkinson's disease. Int Arch Med 1: 2.

52. Yamashita T, Ninomiya M, Hernandez Acosta $P$, Garcia-Verdugo JM, Sunabori T, et al. (2006) Subventricular zone-derived neuroblasts migrate and differentiate into mature neurons in the post-stroke adult striatum. J Neurosci 26: 6627-36.

53. Fritsch B, Reis J, Martinowich K, Schambra HM, Ji Y, et al. (2010) Direct current stimulation promotes BDNF-dependent synaptic plasticity: potential implications for motor learning. Neuron 66: 198-204.

54. Gersner R, Kravetz E, Feil J, Pell G, Zangen A (2011) Long-term effects of repetitive transcranial magnetic stimulation on markers for neuroplasticity: differential outcomes in anesthetized and awake animals. J Neurosci 31: 75217526.

55. Muller MB, Toschi N, Kresse AE, Post A, Keck ME (2000) Long-term repetitive transcranial magnetic stimulation increases the expression of brain-derived neurotrophic factor and cholecystokinin mRNA, but not neuropeptide tyrosine mRNA in specific areas of rat brain. Neuropsychophyrmacology 23: 205-215.
56. Clarkson AN, Overman JJ, Zhong S, Mueller R, Lynch D, et al. (2011) AMPA receptor-induced local brain-derived neurotrophic factor signaling mediates motor recovery after stroke. J Neurosci 31: 3766-3775.

57. Vizi ES (2000) Role of high-affinity receptors and membrane transporters in nonsynaptic communication and drug action in the central nervous system. Pharmacol Rev 52: 63-89.

58. Stagg CJ, Wylezinska M, Matthews PM, Johansen-Berg H, Jezzard P, et al. (2009) Neurochemical effects of theta burst stimulation as assessed by magnetic resonance spectroscopy. J Neurophysiol 101: 2872-2877.

59. Yue L, Xiao-Lin H, Tao S (2009) The effects of chronic repetitive transcranial magnetic stimulation on glutamate and gamma-aminobutyric acid in rat brain. Brain Res.

60. Michael N, Gosling M, Reutemann M, Kersting A, Heindel W, et al. (2003) Metabolic changes after repetitive transcranial magnetic stimulation (rTMS) of the left prefrontal cortex: a sham-controlled proton magnetic resonance spectroscopy (1H MRS) study of healthy brain. Eur J Neurosci 17: 2462-2468.

61. Stagg CJ, Bachtiar V, Johansen-Berg H (2011) The role of GABA in human motor learning. Curr Biol 21: 480-484.

62. Hamada M, Murase N, Hasan A, Balaratnam M, Rothwell JC (2013) The role of interneuron networks in driving human motor cortical plasticity. Cereb Cortex 23: 1593-1605. 